\title{
Early Departure, Early Revival: A "Free From Care" Account of Negative Temporal Discounting
}

\author{
Hai-Long Sun ${ }^{1,2 \#}$, Ai-Mei Li $i^{2 \#}$, Si-Chu Shen ${ }^{3,4 \#, ~ G u a n-X i n g ~ X i o n g ~}{ }^{2,8}$, Li-Lin Rao $^{4,5}$, Rui \\ Zheng ${ }^{4},{ }^{5}$ Hong-Yue Sun ${ }^{6}$, Shu Li2,4, \\ ' School of Business, Guangdong University of Foreign Studies, Guangzhou, China \\ ${ }^{2}$ Management School, Jinan University, Guangzhou, China \\ ${ }^{3}$ Department of Psychology, Fujian Normal University, Fuzhou, China \\ ${ }^{4}$ CAS Key Laboratory of Behavioral Science, Institute of Psychology, Chinese Academy of Sciences, Beijing, China \\ ${ }^{5}$ Department of Psychology, University of Chinese Academy of Sciences, Beijing, China \\ ${ }^{6}$ College of Education, Shanghai Normal University, Shanghai, China \\ ${ }^{7}$ Department of Psychology and Behavioral Sciences, Zhejiang University, Hangzhou, China \\ ${ }^{8}$ School of Economics and Management, South China Normal University, Guangzhou, China. \\ "These authors contributed equally to this work.
}

ABSTRACT

According to the positive temporal discounting theory and our relevant observations, when faced with future losses, people should, and do, prefer delayed negative events (e.g., deferring paying taxes, debts, or tickets), which can lead to substantial individual and societal costs. However, a counterexample has been identified and it appears to depart from the prediction of positive temporal discounting when faced with negative events. This study proposed and investigated the novel free from care account for the reverse preference. Results of five laboratory and field studies showed that students preferred an immediate negative event (i.e., an English oral exam) when "something tying one up" was imposed, in which coping with a distraction induced by such a situation could play a mediating role. In particular, the addition of "something tying one up" was found to be an effective behavioral nudge in terms of reliability and reproducibility and should be simple for potential users to follow. Specifically, the association between being tied up and undergoing a negative event immediately in the present studies mirrored the association between outgroup threat and intergroup cooperation in the Robbers Cave experiment.

\section{KEYWORDS}

negative temporal discounting preference for immediate

negative event

"free from care" account

nudge

intertemporal choice

\section{INTRODUCTION}

People have always made tradeoffs between consequences that occur at different time points; such a decision is called intertemporal choice (Frederick et al., 2002). Intertemporal choice is ubiquitous in daily decision-making and ranges from positive (e.g., monetary gains, health gains, etc.) to negative (e.g., monetary losses, pain, etc.) outcomes. Standard economic theory posits that temporal discounting is a critical component of intertemporal choices (Franco-Watkins et al., 2015). Temporal discounting refers to people's tendency to discount the value of delayed outcomes based on the amount of time required to wait for them, thereby reducing the subjective value of such outcomes. The degree to which the value of a delayed outcome is discounted has been described within several models, such as the discounted utility model, generalized hyperbolic discounting model, proportional discounting model, and quasi-hyperbolic discounting model (Harvey, 1994; Loewenstein \& Prelec, 1992; Mazur, 1984). Although the above-mentioned estimated functional forms presumably differ across investigations, scholars have generally referred to this discounting phenomenon as positive temporal discounting (Loewenstein \& Prelec, 1993). On the basis of positive temporal discounting, earlier rewards are better than later ones and later losses are better than earlier ones. Consistently, most

Corresponding author: Shu Li, CAS Key Laboratory of Behavioral Science, Institute of Psychology, Chinese Academy of Sciences, Beijing 100101, China. E-mail: lishu@psych.ac.cn; Hong-Yue Sun, College of Education, Shanghai Normal University, Shanghai, China. E-mail: sunhy@shnu.edu.cn. 
laboratory studies on intertemporal choice with monetary outcomes find that people generally tend to advance gains and postpone losses (Thaler, 1981; Frederick et al., 2002).

However, an increasing number of findings, especially on negative nonmonetary outcomes, have disconfirmed the phenomenon of positive temporal discounting and suggested that people often exhibit the opposite pattern (Mischel et al., 1969; Harris, 2012; Sun et al., 2015), that is, individuals are more likely to hasten the occurrence of unpleasant outcomes. For example, Mischel et al. (1969) asked adult participants to indicate whether they preferred immediate or delayed aversive experiences, such as eating a bad-tasting food, drinking a bitter liquid, or experiencing a painful cold pressor task; responses suggested that most participants would prefer to encounter these unpleasant experiences immediately. Loewenstein (1987) asked participants to indicate the amount of money they were willing to pay to prevent experiencing electric shocks, which were delayed from 0 to 10 years. The mean price they were willing to pay to avoid a shock was significantly higher for a 1-year delay and 10-year delay compared with shorter-term delays. Berns et al. (2006) found that participants preferred receiving a highervoltage electric shock compared to waiting. Harris (2012) reported that many preferred to hasten certain negative experiences. Researchers have termed this phenomenon as negative temporal discounting (Mischel et al., 1969; Loewenstein, 1987; Harris, 2012; Sun et al., 2015).

\section{Possible Accounts}

Mischel et al. (1969) interpreted negative discounting as a reflection of effort to avoid the waiting process because waiting for an aversive outcome is aversive in itself. Similarly, Loewenstein (1987) pointed out in a theoretical model that participants may experience anticipated dread (coined anticipal pain by Jevons, 1905) toward a delayed negative event that renders the delayed negative event more aversive than an immediate negative event. Harris (2012) further speculated that dread, distinct from fear, is "a broad array of emotions and cognitions besides fear" (p. 27). Although these studies proposed that dread is a potential mechanism of negative discounting, there is hardly any empirical evidence on what dread is and what emotions and cognitions it contains. Recently, Sun et al. (2015) attempted to explore whether an outgrowth was generated to accompany the delayed negative events. Content analysis revealed that the investigated outgrowth consisted of two components. The first component was the anticipated negative emotions elicited by the delayed negative event, and the other was the anticipated rumination during the waiting process in which one cannot stop thinking about the negative event. The subsequent studies in Sun et al. (2015) then measured the negative emotions elicited by the delayed negative event and the role they played in explaining negative temporal discounting. However, the role played by anticipated rumination in explaining negative temporal discounting during the waiting process was not investigated further.

Following Sun et al. (2015)'s logic that adding negative emotions (first component) will nudge people to choose to experience unpleasant experiences sooner, the aim of the present study was to take rumination (the other component) discovered by Sun et al. (2015) as a starting point to test whether their logic is also applicable to it.
Kahneman (1973) contended that each individual has a unique and finite capacity to attend to a given stimulus. Emotion regulation can then be regarded as a task that uses cognitive resources, which could compromise cognitive performance (Gross \& Levenson, 1997). Therefore, we reasoned that, in the face of a negative event, if the event was not eliminated (i.e., either undergone or removed) earlier, then rumination during the waiting process would occupy an individual's limited cognitive resources, which are needed to achieve efficient task performance and thus influence the completion of succeeding events (which we referred to as "something tying one up").

To nudge people to experience unpleasant experiences sooner, additional "rumination" on "something tying one up" was manipulated to attach to the existed rumination induced by the negative event. We speculated that the succeeding events following the negative event would add to the rumination during the waiting process, which, in turn, would make the burden of limited cognitive resources heavier. Our research hypothesis was thus as follows: In the event that adding negative emotions will nudge people to experience unpleasant experiences sooner, the rumination added in the waiting process will also make people choose to experience the unpleasant experiences sooner. Then, we developed and proposed a free from care account of negative temporal discounting. In this context, the term "free from care" refers to the elimination of negative events (i.e., early departure) to clear off the existing rumination induced by such events and to free up attention resources to cope with "something tying one up"-the new "rumination" (i.e., early revival)

\section{Overview}

In this research, the goal was to shed light on the role of rumination (the free from care account) in explaining negative temporal discounting through five studies. Study 1 validated the existence of negative temporal discounting. Studies 2 and 3 examined the possible effect of the presence (or degree of care) of something tying one up on one's preference for an immediate negative event. Within these studies, we also investigated the mediation mechanism of this possible effect, suggested by the free from care account. Study 4 investigated boundary conditions (timing) of the effect of something tying one up on one's preference for an immediate negative event. Study 5 involved a field study to further examine the free from care account. We have reported all measures of variables, experimental manipulations, and exclusion criteria on subjects as well as our method of determining the final sample size.

\section{STUDY 1: COMPLETING AN ENGLISH ORAL EXAM EARLIER OR LATER? PREFERENCE FOR IMMEDIATE NEGATIVE EVENTS}

Study 1 examined whether student participants regarded an English oral exam as a negative event and whether immediate negative events were preferable to delayed negative events. We asked our participants to choose a day within a time interval (i.e., from the first day to the seventh day) to take an English oral exam (drawn from Sun et al., 2015). We then asked them to evaluate whether the offered oral exam constituted a negative event 


\section{Method}

\section{PARTICIPANTS}

We expected an effect size of $d=.40$, as found in Sun et al. (2015). An a priori power analysis using $G^{\star}$ Power (Faul et al., 2009) revealed a required sample size of $N=52$ to detect an effect with high power of $1-\beta=.80$. To account for the potential need to exclude certain participants (due to either failure to complete the study or missing data), 60 undergraduates from a large university in southern China participated in this study in exchange for course credit. No additional stopping rule was used; all analyses were conducted after data were collected. One participant did not complete the study. Thus, our sample contained 59 valid participants (37 women, 22 men) with a mean age of 21.24 years $(S D=1.14)$. Data were analyzed anonymously. No apparent ethical research concerns were identified. Informed oral consent was obtained from all participants before data collection commenced. Participants were also given the opportunity to refuse to participate, skip questions, or withdraw from the study at any time without penalty

\section{MATERIALS AND PROCEDURE}

Materials were prepared in Chinese and presented in questionnaire form. A hypothetical scenario was adapted from Sun et al. (2015), in which an English oral exam was conceived as a negative event. The instruction for choosing a day within a time interval (i.e., from the first day to the seventh day) to take the exam was phrased as follows: "Please imagine that you have to choose a day within the next 7 days ( 1 = first day, 7 = seventh day) to take an oral exam in English whose content and form will be randomly determined."

Participants were asked to (a) choose a day within the next 7 days to take the English oral exam and (b) evaluate whether the exam represented a negative event by circling a number on a 9-point Likert-type scale $(1=$ completely positive $;=$ neutral $; 9=$ completely negative $)$.

\section{Results and Discussion}

\section{RATING RESULTS}

The rating of the English oral exam as a negative event served as a manipulation check. The participants' average rating was 5.71 ( $S D=$ 1.53) on a 9-point scale. A one-sample t-test showed that the average rating of the English oral exam as a negative event was significantly higher than 5 (the hypothetical mean value), $t(58)=3.57, p<.001$, indicating that our Chinese student participants perceived the English oral exam as a negative event. A significant correlation between the participants' rating of the English oral exam and choice of day was then detected, $r=-.27, p=.039$, suggesting that the more negatively the participants perceived the English oral exam, the more likely they were to choose the delayed option for taking it.

Following Hardisty and Pfeffer's (2016) logic, the preference for immediate negative events in the present study and in our subsequent studies was estimated using the average number of days chosen for immediate negative events (i.e., the English oral exam) and the proportion of participants selecting the immediate option.

Participants' responses to the English oral exam scenario are shown in Table 1. Women and men exhibited no significant difference in the average number of days chosen for taking the English oral exam. Hence, we collapsed gender in subsequent analyses. The average number of days the participants chose for taking the English oral exam was $1.86(S D=1.31)$. Choices were not equally distributed across the seven days, $\chi^{2}(5, N=59)=75.34, p<.001, \Phi G=.46$.

Results of Study 1 showed that our participants considered the English oral exam a negative event. This finding is consistent with previous studies (e.g., Siemer, 2008; Sun et al., 2015). For instance, Sun et al. (2015) found that participants preferred to experience negative events sooner rather than later when waiting for a negative event (i.e., a PowerPoint presentation).

\section{STUDY 2: TO CARE OR NOT TO CARE: THE EFFECT OF BEING TIED UP WITH SOMETHING ON ONE'S PREFERENCE FOR AN IMMEDIATE NEGATIVE EVENT AND ITS MEDIATION MECHANISM}

The findings of Study 1 and Sun et al. (2015) provided evidence that participants tended to select an earlier day to take an English oral exam (regarded as a negative event). Yet the mechanism of this possible effect remained unclear. Study 2 and subsequent studies were thus designed to test the free from care account of negative temporal discounting. Drawing upon the theory of limited cognitive resources as well as prior literature (Kahneman, 1973; Sun et al., 2015), we hypothesized that individuals would tend to select an earlier day to take an English oral exam (a negative event) if they had something tying them up (i.e., something to care about) compared with the "nothing tying them up" control condition (Hypothesis 1). Moreover, we supposed that something tying the participants up would exert a significant effect on their preferences when selecting a day to take the English oral exam (a negative event); this effect would presumably be mediated through the distraction and rumination induced by something tying one up (Hypothesis 2).

\begin{tabular}{ccccccccc}
\cline { 2 - 6 } & $\begin{array}{l}\text { TABLE 1. } \\
\text { Preferences for Immediate Negative Events (N=59) }\end{array}$ & \\
\hline & \multicolumn{7}{c}{ Selected day for English oral exam within a certain time interval } \\
\cline { 2 - 7 } & 1 st & 2nd & 3rd & 4th & 5th & 6th & 7th \\
\hline $\begin{array}{c}\text { Number of } \\
\text { participants }\end{array}$ & 33 & 13 & 7 & 2 & 3 & 0 & 1 \\
\hline Frequency (\%) & 55.9 & 22.0 & 11.9 & 3.4 & 5.1 & 0 & 1.7 \\
\hline
\end{tabular}




\section{Method}

\section{PARTICIPANTS}

Following similar empirical research on intertemporal choice, a target sample size of 90 was set to achieve $80 \%$ power ( $\mathrm{G}^{\star}$ Power 3.1 ), assuming Study 2 's effect size ( $d=.60$, Hardisty et al., 2013). We employed this power analysis in Study 2 and all subsequent studies. We recruited 75 undergraduates from a large university in southern China. The participants' mean age was 20.24 years $(S D=1.18)$. Each participant was exposed to one experimental condition. Forty-three participants (31 women, 12 men) were assigned to the "care" condition, and 32 participants ( 22 women, 10 men) were assigned to the "no care" condition (i.e., the control condition). Data were analyzed anonymously. No apparent ethical research concerns were identified. Informed oral consent was obtained from all participants before data collection commenced, and no participants were involved in a similar experiment.

\section{MATERIALS AND PROCEDURE}

The English oral exam scenario from Study 1 was applied in Study 2 to measure the participants' preferences for immediate negative events. Participants were asked to choose a day within a time interval (i.e., from the first day to the seventh day) to take an English oral exam. Their answers were recorded as the dependent variable, as in Study 1.

The independent variable determined whether participants had something tying them up (i.e., something to care about) on the 10th day. In the care condition, participants were provided with the following prompt: "Imagine that you are required to report on a psychological paper from a top-tier journal on the 10th day as part of your coursework." By contrast, participants in the no care condition were provided with the following prompt: "Imagine that you are invited to attend a class meeting with no need to do any organizing work on the 10th day." The experimental paradigm is depicted in Figure 1.

To investigate whether the degree of distraction and rumination was induced by something tying the participants up in the care condition, they rated the extent to which they cared about the paper report/ class meeting on a 9-point Likert-type scale. The item read as follows: "I would ruminate on and get distracted by the class meeting (or paper report) mentioned above $(9=$ extremely high intensity, $1=$ slight intensity)."

\section{Results and Discussion}

\section{CHOICE RESULTS}

The participants' preferences for immediate negative events are displayed in Table 2. Similar to our predictions, participants were more likely to opt to take an English oral exam earlier in the care condition, $M=3.45, S D=2.09$, than in the no care condition, $M=4.59, S D=$ $1.92, t(72)=-2.42, p=.018, d=.57$ (actual effect size was consistent with assuming Study 2's effect size of $d=.60$ ). These results supported Hypothesis 1 and indicated that individuals tended to select an earlier day to participate in a negative event when something was tying them up compared with the control.

\section{MEDIATION ANALYSIS}

To test Hypothesis 2, we first investigated whether the participants were distracted and ruminated in the care condition compared with the no care condition. The average degree of distraction and rumination was 6.23 $(S D=1.46)$ in the care condition and $3.59(S D=1.70)$ in the no care condition. An independent-samples t-test showed that the degree of distraction and rumination was significantly higher in the care condition than in the no care condition, $t(73)=7.21, p<.001, d$ $=1.67$.

Next, we adopted a mediation model to test the indirect effect of care on the participants' preferences for immediate negative events through distraction and rumination. Regression analyses were initially conducted to assess each component of the proposed mediation model, revealing that care was positively associated with distraction and rumination, $B=.65, t(73)=7.21, p<.001$, and "distraction and rumination" was negatively associated with the participants' preferences for the English oral exam, $B=-.38, t(73)=-3.71, p<.001$. Results also indicated that care was negatively associated with the participants' preferences for the exam, $B=-.27, t(73)=-2.42, p<.01$.

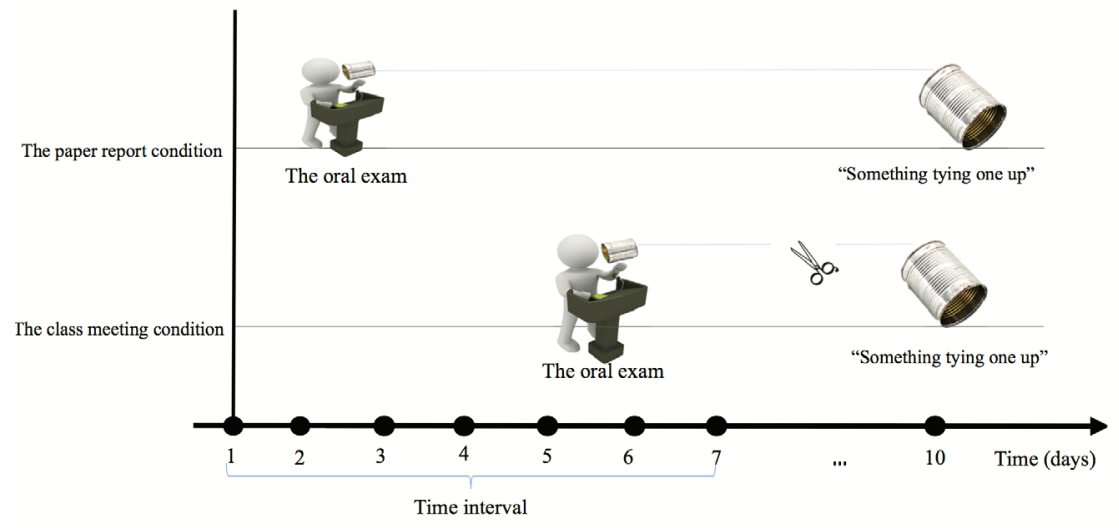

FIGURE 1.

Experimental paradigm used in Study 2. 


\begin{tabular}{cccccccc}
\hline $\begin{array}{l}\text { TABLE 2. } \\
\text { Preferences for Immediate Negative Events in the "Care" and "No Care" Conditions }\end{array}$ \\
\hline \\
\cline { 2 - 8 } & 1 st & 2 2nd & 3 rd & 4 th & 5 th & 6 th & 7 th \\
\hline $\begin{array}{c}\text { Care condition } \\
(N=43)\end{array}$ & $12(27.9 \%)$ & $2(4.7 \%)$ & $\begin{array}{c}8 \\
(18.6 \%)\end{array}$ & $\begin{array}{c}9 \\
(20.9 \%)\end{array}$ & $\begin{array}{c}4 \\
(9.3 \%)\end{array}$ & $0(0 \%)$ & $\begin{array}{c}7 \\
(16.3 \%)\end{array}$ \\
\hline $\begin{array}{c}\text { No care condition } \\
(N=32)\end{array}$ & $2(6.3 \%)$ & $4(12.5 \%)$ & $3(9.4 \%)$ & $\begin{array}{c}6 \\
(18.8 \%)\end{array}$ & $\begin{array}{c}5 \\
(15.6 \%)\end{array}$ & $\begin{array}{c}5 \\
(15.6 \%)\end{array}$ & $\begin{array}{c}7 \\
(21.9 \%)\end{array}$ \\
\hline
\end{tabular}

Mediation analyses were performed using the bootstrapping method with bias-corrected confidence estimates (Preacher \& Hayes, 2004). The $95 \%$ confidence interval of indirect effects was obtained using 5000 bootstrap resamples . Consistent with Hypothesis 2, the findings revealed a mediating role of distraction and rumination in the relationship between care and the participants' preferences for the English oral exam, $B=-.25$; CI: $[-.431,-.064]$ (see Figure 2). The results suggested that the participants who had something tying them up perceived it as entailing rumination and distraction, which increased their preferences for immediate negative events as a means of conserving limited cognitive resources.

Previous results have suggested that in the case of something tying one up, people prefer to eliminate the negative event earlier. However, limited direct evidence has supported the hypothesis that (a) a negative event and something tying one up each occupy limited cognitive resources and that $(b)$ individuals must therefore eliminate the negative event to conserve time and energy to subsequently deal with something tying one up. Study 2 provides initial evidence that an observed preference for an immediate negative event could be explained by a free from care account. In Study 2, our manipulation of the independent variable (care) was accomplished by assigning participants different tasks involving distinct time/energy requirements. However, some confounding variables in our data (i.e., emotions) must be addressed further. Although we do not think that this variable affected our conclusions, we examined the robustness of our findings through Study 3. In this study, we manipulated the independent variable by inducing different degrees of care in a single task and rating negative and positive emotions about the negative event (i.e., an English oral exam).

\section{STUDY 3: TO CARE MORE OR TO CARE LESS? THE EFFECT OF THE DEGREE OF BEING TIED UP WITH SOMETHING ON THE PREFERENCE FOR AN IMMEDIATE NEGATIVE EVENT AND ITS MEDIATION MECHANISM}

\section{Method}

\section{PARTICIPANTS}

Building on the results of Study 2, we considered a large-sized effect of processing mode to be the minimal effect of meaningful magnitude. A target sample size of 84 was set to achieve $80 \%$ power ( $\mathrm{G}^{\star}$ Power 3.1 ). Correspondingly, 96 undergraduate students from a large university in southern China participated in the study in exchange for course credit. Seven participants did not complete the study and were excluded from the dataset, leaving 89 participants (69 women, 20 men) for further analysis. The participants' mean age was 21.63 years $(S D=1.99)$. No participants were involved in a similar experiment.

\section{MATERIALS AND PROCEDURE}

This study used a single-factor, between-subjects design. The dependent variable was the preference for immediate negative events, and the independent variable was the degree of care about being tied up with something. Measurement of the independent variable was borrowed and modified from the class meeting task in Study 2. We adopted the previous task (class meeting) as one of the three care levels

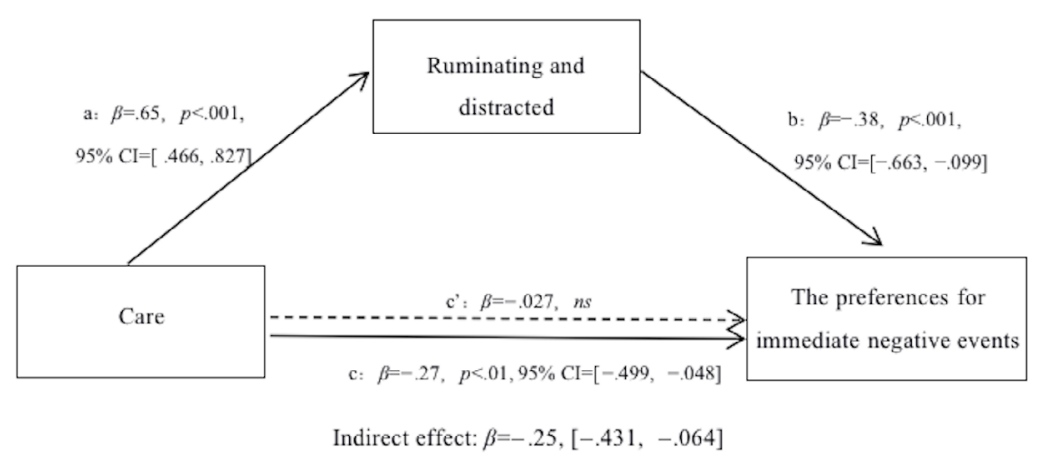

FIGURE 2.

Indirect effect of "care" on the "preferences for immediate negative events" through "ruminating and distracted" in Study 2. Note: $1=$ "to care" condition, 0 ="not to care". 


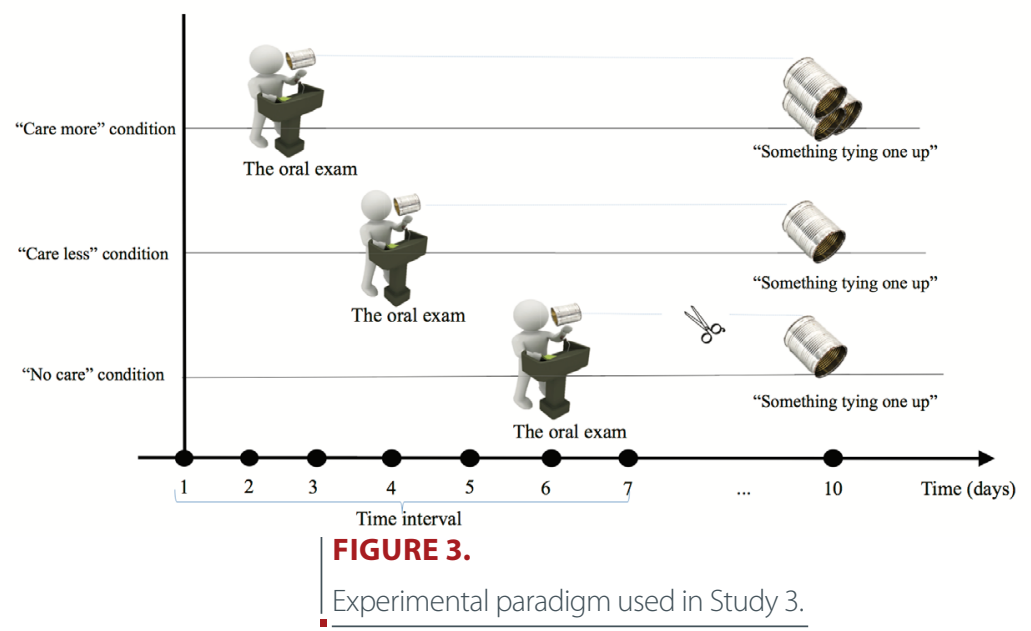

(i.e., the no care condition) of the independent variable; the other two care levels were "care less" and "care more" (see Figure 3).

Instructions for measuring the independent variable at the three care levels were identical except for the italicized sentence in parentheses: "Imagine that you are invited to attend a class meeting on the 10th day. ([Italicized sentence])."

1) In the no care condition, the sentence in parentheses was As a class member, you do not need to do any organizing work.

2) In the care less condition, the sentence in parentheses was As a monitor assistant, you need to (a) draft the meeting plan, (b) make the hotel reservation, and (c) take a head count.

3) In the care more condition, the sentence in parentheses was As a class monitor, you need to (a) draft the meeting plan, (b) draft the activity procedure, (c) make the hotel reservation, (d) take a head count, (e) raise money for the meeting, and $(f)$ purchase drinks and other items.

Thirty participants ( 28 women, 2 men), 27 participants (18 women, 9 men), and 32 participants ( 23 women, 9 men) were respectively assigned to the care less, no care, and care more conditions. All 89 participants responded to the same dependent variable for each of the three conditions. The dependent variable in this study, namely, one's preference for an immediate English oral exam, was the same as in Studies 1 and 2. We also asked participants to (a) choose a day within the next 7 days to take an imposed oral exam, (b) evaluate their degree of distraction and rumination about the class meeting task on a 9-point Likerttype scale $(1=$ not at all, $9=$ very $m u c h)$, and (c) rate their emotions about the English oral exam. Following the measurement adopted in Sun et al. (2015), participants rated the oral exam as eliciting negative emotions (i.e., anxiety and worry) and positive emotions (i.e., happiness and excitement). Participants were asked to rate the intensity of these four emotions on a 9-point scale ranging from 1 (not intense at all) to 9 (extremely high intensity).

\section{Results and Discussion}

\section{CHOICE RESULTS}

The participants' preferences for immediate negative events are listed in Table 3. The average number of days chosen before taking the English oral exam was $3.19(S D=1.26)$ in the care more condition, 3.97 $(S D=1.77)$ in the care less condition, and $4.33(S D=1.57)$ in the no care condition. These results supported our predictions and revealed a significant difference in the average number of days across conditions, $F(2,86)=4.33, p=.016$. A post-hoc analysis conducted on these data showed that the average number of days chosen in the care more condition was significantly earlier than in the care less $(p=.05)$ and no care $(p=.006)$ conditions.

We also aggregated different positive/negative emotions and performed an analysis of variance (ANOVA) to examine the effect of each emotion type (i.e., positive and negative) on each care condition. Regarding the mean intensity of emotions in the negative event across different care conditions, a $3 \times 2$ (Condition [care more, care less,

\section{TABLE 3.}

Preferences for Immediate Negative Events Across the Care More, Care Less, and No Care Conditions in Study 3

\begin{tabular}{cccccccc}
\hline & \multicolumn{6}{c}{ Selected day for English oral exam within a certain time interval } \\
\cline { 2 - 8 } & 1 st & 2nd & 3rd & 4th & 5th & 6th & 7 th \\
\hline $\begin{array}{c}\text { Care more condition } \\
(N=32)\end{array}$ & $3(9.4 \%)$ & $6(18.8 \%)$ & $10(31.3 \%)$ & $10(31.3 \%)$ & $1(3.1 \%)$ & $2(6.3 \%)$ & $7(21.9 \%)$ \\
\hline $\begin{array}{c}\text { Care less condition } \\
(N=30)\end{array}$ & $2(6.7 \%)$ & $3(10.0 \%)$ & $8(26.7 \%)$ & $10(33.3 \%)$ & $0(0 \%)$ & $2(6.3 \%)$ & $5(16.7 \%)$ \\
\hline $\begin{array}{c}\text { No care condition } \\
(N=27)\end{array}$ & $2(7.4 \%)$ & $1(3.7 \%)$ & $3(11.1 \%)$ & $9(33.3 \%)$ & $7(25.9 \%)$ & $2(7.4 \%)$ & $3(11.1 \%)$ \\
\hline
\end{tabular}


and no care] $\times 2$ Valence [positive andnegative ]) repeated-measures ANOVA only revealed a significant effect of valence, $F(1,80)=48.06$, $p<.001, \eta_{\mathrm{p}}^{2}=.38$, indicating that the oral exam elicited negative emotions $(5.57 \pm 1.62)$ to a significantly greater extent than it did positive emotions (3.66 \pm 1.95$)$. The resulting emotion rating further substantiated the conclusion that participants in this study likely perceived the English oral exam as a relatively negative event.

\section{MEDIATION ANALYSIS}

The free from care account postulates that individuals must cope with something tying them up, which is distracting and can lead to rumination. Thus, these individuals must accomplish the negative event earlier to conserve limited cognitive resources to deal with the subsequent task tying them up.

To test this supposition, we first investigated whether individuals would be distracted and ruminate more under conditions with a higher degree of care. The degree of distraction and rumination was $5.44(S D=1.97)$ in the care more condition, $4.47(S D=1.76)$ in the care less condition, and $3.11(S D=1.89)$ in the no care condition. A oneway ANOVA revealed that the degree of distraction and rumination differed significantly across conditions, $F(2,86)=11.31, p<.001, \eta_{p}^{2}$ $=.21$. A post-hoc analysis of these data showed that the degree of distraction and rumination in the care more condition was significantly higher than in the care less $(p=.045)$ and no care conditions $(p<.001)$.

To further explore our hypothesis, we conducted a mediation analysis to investigate the effect of distraction and rumination induced by something tying one up on the relationship between care conditions and the preference for the negative event. Mediation analyses were performed using the bootstrapping method with bias-corrected confidence estimates to test the mechanism of distraction and rumination (Preacher \& Hayes, 2004). First, we found the care more, care less, and no care conditions to be negatively associated with the participants' preferences for immediate negative events, $B=-.69, t(88)=-2.89, p<$ .001 . Simultaneously, the care more, care less, and no care conditions were positively related to distraction and rumination, $B=.45, t(88)$ $=4.76, p<.001$. The results of the mediation analysis confirmed the mediating role of distraction and rumination in the relation between care more, care less, and no care conditions, and the participants' preferences for immediate negative events, $B=-.32$; CI: [-.471, -.178$]$ (see Figure 4).

Based on the findings of Study 2, which used two different tasks, Study 3 was designed to further investigate the participants' preferences for immediate negative events by manipulating the degree of being tied up with something in a single task. These two studies confirmed our expectations that participants were more likely to opt to experience a negative event (oral exam) earlier when tied up with something (in either the care or care more condition). In other words, when participants expected to experience a negative event and a subsequent care event that would occupy their energy and time, they were more likely to choose to experience the negative event earlier in order to devote more attention to the subsequent tasks about which they cared. This observed preference pattern was consistent with the predictions of the free from care account.

\section{STUDY 4: WITHIN OR BEYOND TIME IN- TERVAL? THE BOUNDARY CONDITIONS OF 'BEING TIED UP WITH SOMETHING' ON THE PREFERENCE FOR AN IMMEDI- ATE NEGATIVE EVENT}

Studies 2 and 3 indicated that when the degree of care around something tying one up was manipulated to be high, the participants chose to experience the negative event immediately. In Study 4, we further manipulated the timing of something tying one up to evaluate the boundary conditions of its possible effect on one's preference for an immediate negative event. According to the free from care account, the purpose of removing the negative event (i.e., early departure) earlier is to reserve more time and energy to accomplish something tying one up (i.e., early revival).

Based on this logic, we assumed that the timing of being tied up with something would affect the participants' preferences for an immediate negative event. In other words, only when the class meeting (something tying one up) occurred beyond the time interval (in our series of studies, the time interval was consistently set from the first

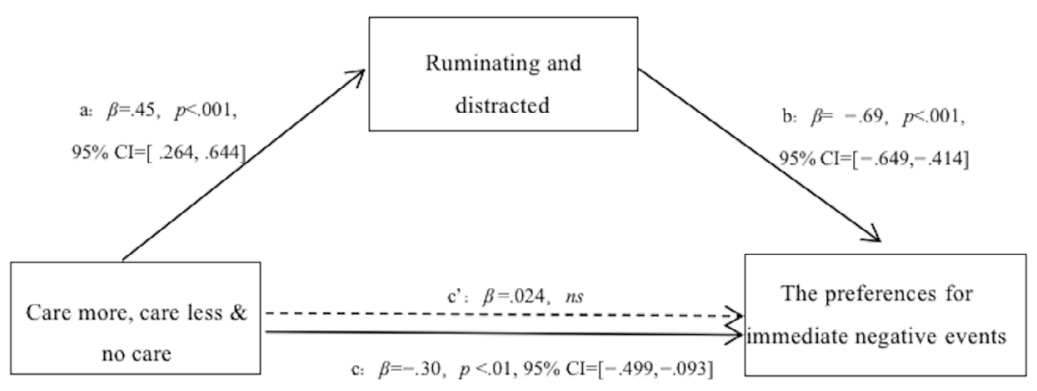

FIGURE 4.

Indirect effect: $\beta=-.32,[-.471,-.178]$

Indirect effect of "care more, care less and no care" on the "preferences for immediate negative events"through "ruminating and distracted" in Study 3. 


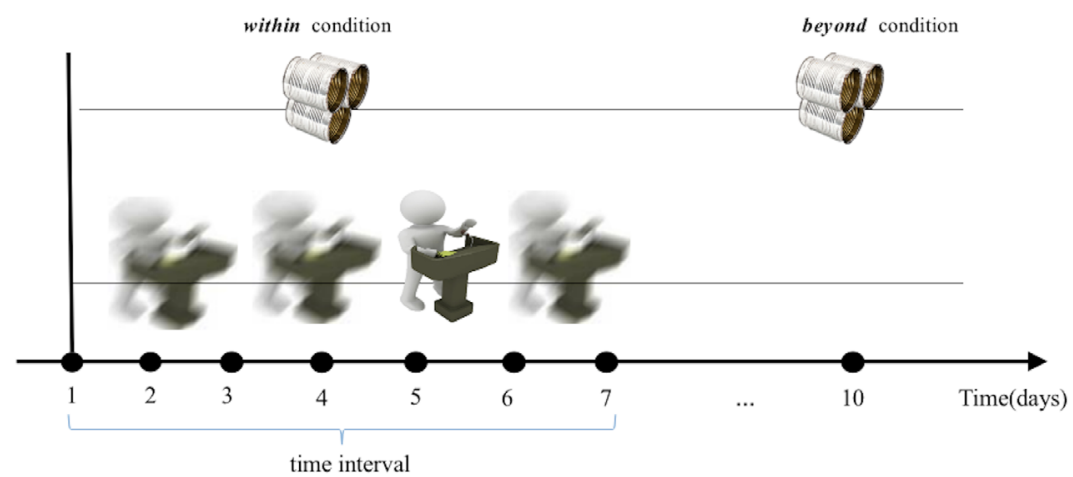

FIGURE 5.

Experimental paradigm used in Study 4.

to the seventh day) would selecting an earlier day for the English oral exam (negative event; i.e., early departure) make sense. This condition was set because immediately completing an English oral exam (negative event) could provide additional time-energy space to cope with the class meeting (something tying one up; i.e., early revival).

If the class meeting (something tying one up) occurred within the time interval, then the following possibilities were likely:

(a) The participants were not likely to choose to take the English oral exam (negative event) on the same day as the class meeting (something tying them up) because the class meeting would distract them from the exam.

(b) The participants were most likely to choose to take the English oral exam (negative event) after the class meeting (something tying them up) because undergoing a later oral exam (negative event) would leave more time-energy space to cope with the exam (negative event) itself.

We then proposed two additional working hypotheses:

H3: If the class meeting (something tying one up) occurred beyond the time interval, then the participants would be likely to select an earlier day for the English oral exam (negative event; i.e., early departure).

$\mathrm{H} 4$ : If the class meeting (something tying one up) occurred within the time interval (for example, the 4 th day), then the participants (a) would be unlikely to take the English oral exam (negative event) on the same day as the class meeting (something tying one up) and (b) would tend to select a later day for the exam (negative event; i.e., later departure)

\section{Method}

\section{PARTICIPANTS}

The target sample size in this study was 90 , calculated using an a priori power analysis for an independent samples t-test with a high power of $1-\beta=.80$, based on the effect size obtained by Hardisty et al. (2013; $d=.60$ ). Eighty-five undergraduates (46 women, 39 men) from a large university in southern China participated in the study in exchange for course credit. Although our final sample size was slightly smaller than required, we still obtained sufficient statistical power (i.e., $1-\beta=.92$ ) to detect the effect of relevant magnitude. Data analyses were conducted after data collection. No other stopping rule was used. The participants' mean age was 21.28 years $(S D=1.73)$, and none were involved in a similar experiment.

\section{MATERIALS AND PROCEDURE}

In the present study, the dependent variable consisted of the participants' preferences for immediate negative events, with the negative event following the English oral exam scenario in our previous studies. The class meeting (something tying one up) task used in Studies 2 and 3 was employed in this study as the independent variable. The independent variable was the care more condition (i.e., organizing the class meeting as a class monitor) from Study 3. In our previous studies, all instances of the class meeting (something tying one up) occurred beyond the time interval for the English oral exam. However, in this study, the class meeting (something tying one up) occurred either beyond or within the time interval for the exam. We formed two levels or conditions for this independent variable. In the "within" condition, the class meeting (something tying one up) occurred on the 4th day, whereas it occurred on the 10th day in the "beyond" condition (see Figure 5 ). The interval between the timing of the "care" event (the 4th and 10th day, respectively) and the deadline of the negative event (the 7th day) was equal, enabling us to control the influence of the confounding variable (i.e., time interval).

Each participant was exposed to one experimental condition in the class meeting task. Forty-eight participants (35 women, 13 men) were assigned to the within condition, and 37 participants (11 women, 26 men) were assigned to the beyond condition.

\section{Results and Discussion}

The participants' preferences for immediate negative events in the two conditions relative to the timing of something tying one up are shown in Table 4. The average number of days chosen for taking the English oral exam was $4.83(S D=2.21)$ in the within condition and $3.35(S D=$ 1.69) in the beyond condition. An independent-samples t-test revealed a significant difference between the conditions, $t(83)=3.51, p<.001$, $d=.75$. These findings lend support to our $\mathrm{H} 3$ and indicate that the 


\begin{tabular}{|c|c|c|c|c|c|c|c|}
\hline & \multicolumn{6}{|c|}{$\begin{array}{l}\text { TABLE } 4 . \\
\text { Preferences for Immediate Negative Events }\end{array}$} & \\
\hline & \multicolumn{7}{|c|}{ Selected day for English oral exam within a certain time interval } \\
\hline & 1 st & 2nd & 3rd & 4 th & 5 th & 6th & 7th \\
\hline $\begin{array}{l}\text { Within the time interval } \\
\text { (for English oral exam) } \\
\qquad(\mathrm{N}=48)\end{array}$ & $4(8.3 \%)$ & $6(12.5 \%)$ & $8(16.7 \%)$ & $1(2.1 \%)$ & $4(8.3 \%)$ & $7(14.6 \%)$ & $18(37.5 \%)$ \\
\hline $\begin{array}{l}\text { Beyond the time interval } \\
\text { (for English oral exam) } \\
\qquad(\mathrm{N}=37)\end{array}$ & $7(18.9 \%)$ & $4(10.8 \%)$ & $10(27 \%)$ & $6(16.2 \%)$ & $7(18.9 \%)$ & $1(2.7 \%)$ & $2(5.4 \%)$ \\
\hline
\end{tabular}

participants were likely to select an earlier day for the negative event when something tying them up occurred beyond the time interval (compared to within the time interval). Consistent with our $\mathrm{H} 4$, when the class meeting occurred within the time interval (i.e., the 4th day), only one participant chose to take the oral exam on the same day as the meeting.

As expected, the participants tended to choose to take an English oral exam (negative event) earlier (i.e., early departure). According to the free from care account, this scenario occurred because they needed to reserve time-energy space to leave more room for the class meeting (something tying them up); otherwise, the so-called early revival (facilitating the class meeting well) would not be possible.

Compared with Studies 2 and 3, Study 4 manipulated the timing of a care event (either beyond or within the time interval condition) without changing the degree of care to investigate the boundary conditions of being tied up with something on the participants' preferences for an immediate negative event. The results from Study 4 supported our two working hypotheses (H3 and 4) from a new perspective. Despite these strengths, the external validity of Studies 1 through 4 could be criticized because the independent and dependent variables were measured on the basis of a hypothetical scenario. Thus, the question of whether our effects can be generalized outside a laboratory environment remained unanswered. To address this concern, Study 5 sought to confirm our results in a field setting.

\section{STUDY 5 (FIELD STUDY): INTERTEM- PORAL CHOICE WITH REAL NEGATIVE EVENTS AND REAL THINGS TO BE TIED UP WITH}

In this study, we aimed to examine the free from care account of negative temporal discounting in a field setting. For this purpose, a class of students majoring in educational psychology at a large university in southern China was selected. Their course lecturer was a confederate researcher who performed this study. The educational psychology course was scheduled to last 20 weeks, including 120 minutes of lecture per week. The final exams for all courses at the university were scheduled during the 21st week (January 18, 2016). Students were required to take two oral exams (10 minutes each) during two time intervals (at the beginning and end of the semester) to meet course requirements. Each student was asked in advance to select a week from each of the two scheduled time intervals to take the English oral exam, which accounted for $80 \%$ of their total course credit. Students could not prepare for the exam in advance because the concepts to be examined extended beyond textbook knowledge. These course features left the possibility that the degree of being tied up with something (i.e., the final exam $[\mathrm{s}]$ ), as the independent variable, could be manipulated by scheduling the English oral exam at the beginning and end of the semester.

Study 5 differed from our previous studies in several aspects. First, the negative event (dependent variable: oral exam) was not a hypothetical scenario but a real oral exam. After the participants selected a specific week to take the English oral exam within a time interval (from the first week to the sixth week), they had to take the exam. Second, the "something tying one up" condition was also not hypothetical but real (i.e., the final exam[s] taken by students). The independent variable, namely, the degree of care around being tied up with something, was manipulated by scheduling the English oral exam within six weeks at the beginning and end of the semester (see Figure 6). On one hand, we speculated that at the beginning of the semester, the final exams in various courses would be so far away that the students would deem them "care less" events. On the other hand, at the end of the semester, final exams would be so near that they would be considered "care more" events. Our field study took place from October 8, 2015 to January 18, 2016.

\section{Method}

\section{PARTICIPANTS}

Given the number of students in the educational psychology class, 50 participants ( 33 women, 17 men) participated in this field study. The mean age of the participants was 20.68 years $(S D=0.89)$. For ecological validity, the participants were not given any incentive (e.g., course credit or a gift voucher) in order to ensure they were unaware of the experiment.

\section{PROCEDURE}

This study employed a within-subject design. Each participant responded to the dependent variable item of "Which week will you select to take one of the two oral exams?" The educational psychology course lecturer (i.e., the confederate researcher) arranged two oral exams during the semester and offered two time intervals (first exam: from October 8, 2015 to November 12, 2015; second exam: from December 10, 2015 to January 14, 2016; see Figure 6). 


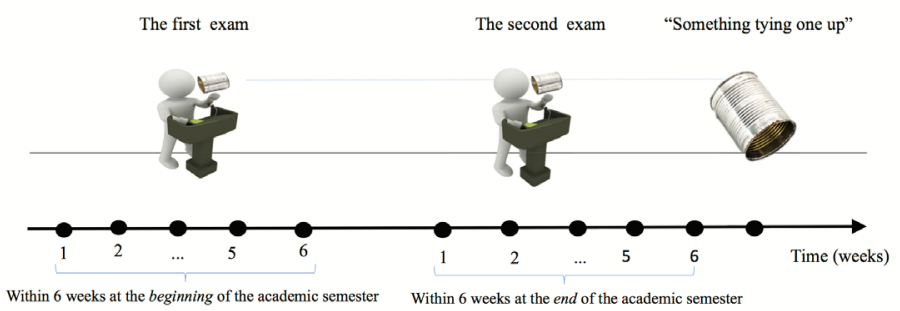

FIGURE 6.

Experimental paradigm used in Study 5.

To determine the extent to which final exams tied the participants up at the beginning and end of the semester and to avoid priming the participants that the default final exam was used in our experiment as something tying one up, 30 additional students (12 women, $18 \mathrm{men} ; M_{\text {age }}$ $=21.0, S D=1.20)$ from a parallel class of the same grade were asked, at the 6th and 15th academic weeks, to rate the extent to which they cared about the final exams on a 9-point scale $(1=$ not at all; $9=$ very much $)$.

\section{Results and Discussion}

\section{MANIPULATION CHECK}

The degree of care was $3.60(S D=1.85)$ for the final exam rated at the beginning of the semester and $5.87(S D=1.61)$ for the final exam rated at the end of the semester. A paired -samples t-test showed that the degree of care at the beginning of the semester was significantly lower than that at the end of the semester, $t(29)=-5.50, p<.001$. These results indicated the effectiveness of the manipulation of the timeallocation rationale in each condition.

\section{CHOICE RESULTS}

The participants' preferences for immediate negative events in the field study are shown in Table 5. The average number of weeks chosen for taking the English oral exam was $3.80(S D=1.46)$ for the first exam (at the beginning of the semester) and $1.76(S D=.59)$ for the second exam (at the end of the semester). A paired-samples $t$-test revealed a significant difference between the two conditions, $t(49)=9.91, p<.001$.

We further grouped the first, second, and third weeks within each time interval as the immediate option and the fourth, fifth, and sixth weeks as the delayed option. For the first exam, $66 \%$ of the 50 participants preferred the delayed option. In contrast, the participants did not choose the delayed option for the second exam (see Figure 7). A $2 \times$ 2 (Condition [immediate option, delayed option] $\times$ Preference [first exam, second exam]) McNemar test revealed a significant relationship between condition and preference, $\chi^{2}(1, \mathrm{~N}=50)=31.03, p<.001$. These results indicated that the participants were more likely to choose to experience a negative event (oral exam) earlier when something tying them up was imposed at the end of the semester (second exam) but preferred to experience a negative event later when something tying them up was imposed at the beginning of the semester (first exam).

The goal of Study 5, which sought to confirm our results in a field setting, was achieved with student participants who were unaware of independent-variable manipulation (i.e., the degree of being tied up with something). The advantage of Study 5 was that it switched the interval between the date of the English oral exam and the date of the final exam in subtle ways in order to unconsciously nudge the participants toward different degrees of care regarding the actual final exam (being tied up with something). If we did not interpret the present findings from the perspective of the free from care account, it would be difficult to explain why the observed intertemporal preferences for the same negative event differed between the beginning and end of the semester.

\section{GENERAL DISCUSSION}

According to the discounting model, positive discounting of future losses occurs when individuals delay an immediate negative event (Harvey, 1994; Loewenstein \& Prelec, 1992; Mazur, 1984). In reality, people commonly delay future negative events, especially when facing the negative nonmonetary outcomes. Undergoing unpleasant experiences later (e.g., postponing a vaccination to avoid the pain of a

\section{TABLE 5.}

Temporal Preferences for Taking the English Oral Exam Within 6 Weeks at the Beginning and End of the Academic Semester

\begin{tabular}{ccccccc}
\hline & \multicolumn{5}{c}{ Selected day for English oral exam within a certain time interval } \\
\cline { 2 - 7 } & 1st & 2nd & 3rd & 4th & 5th & 6th \\
\hline $\begin{array}{c}\text { First exam (within 6 weeks of } \\
\text { the beginning of the semester) }\end{array}$ & $4(8 \%)$ & $7(14 \%)$ & $6(12 \%)$ & $18(36 \%)$ & $8(16 \%)$ & $7(14 \%)$ \\
\hline $\begin{array}{c}\text { Second exam (within 6 weeks } \\
\text { of the end of the semester) }\end{array}$ & $16(32 \%)$ & $30(60 \%)$ & $4(8 \%)$ & $0(0 \%)$ & $0(0 \%)$ & $0(0 \%)$ \\
\hline
\end{tabular}




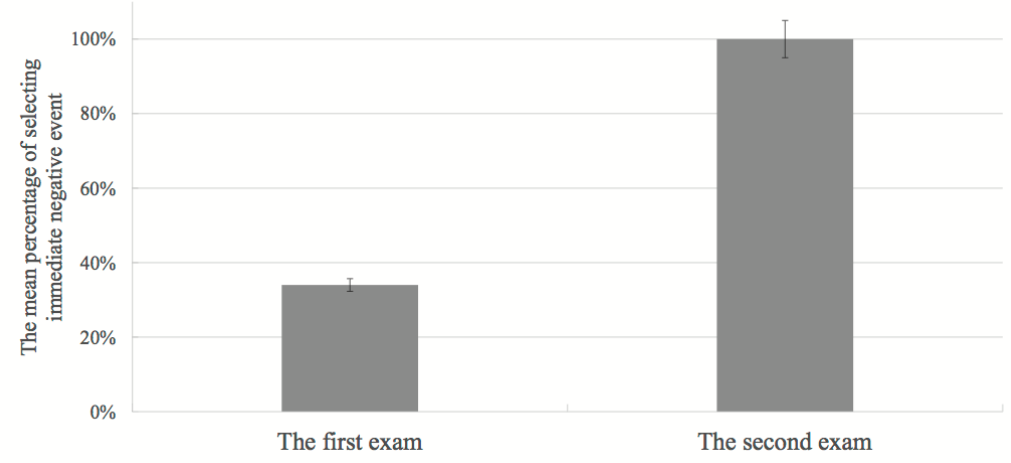

FIGURE 7.

Mean percentage of selecting the immediate option in conditions of different times in Study 5. Error bars indicate \pm one SE.

needle prick; deferring paying a fine and defaulting on a loan; postponing schoolwork) has been implicated in many problematic behaviors in healthy/normal, developing, and clinical populations, resulting in substantial individual and societal costs. In this sense, the reverse preference (undergoing unpleasant experiences immediately, i.e., negative discounting) contradicts the discounting model and should be promoted, given its social and economic value. Despite the growing knowledge of the psychological processes involved, little is known about the reason and manner in which excessive positive discounting operates, not to mention negative discounting of future losses. To search for a particular intervention consistent with negative discounting of future losses, the present studies investigated a novel account of negative temporal discounting (i.e., the free from care account) to help people make temporal choices that are beneficial to individuals and society.

We conducted five studies to examine the free from care account. Study 1 found that the participants indicated a preference to experience a negative event sooner rather than later. Study 2 revealed that the participants were likely to hasten a negative event when they would be tied up in the future; direct evidence indicated that coping with a distraction induced by something tying one up could play a mediating role in this response pattern. Study 3 further manipulated the degree of being tied up with something and found that the participants in the care more condition chose to experience a negative event earlier than those in the care less condition.

The corresponding mediation analysis revealed that something tying the participants up enhanced their preferences for immediate negative experiences via the induced distraction and rumination. In Study 4, we found that the timing of being tied up with something affected the participants' preference for an immediate negative event. These findings clarify our free from care account by suggesting that the purpose of eliminating a negative event sooner is to devote sufficient time and energy to subsequent events (i.e., early departure). Early departure would be unnecessary if the event tying one up (e.g., facilitating a class meeting well) occurred before the negative event, that is, under the condition that the class meeting occurred within the time interval (i.e., the 4th day), the aforementioned effect was unlikely to be extracted or otherwise detected. Lastly, we replicated our results in a field study.
Classical decision theory assumes that decision options are characterized by a set of dimensions (or attributes) that remain unchanged (Kahneman \& Tversky, 2000); choices are presumably guided by the principle of value maximization (Luce, 1959). However, some researchers have explained paradoxical choices from the perspective of modifying the representation space. These scholars have also offered evidence that decision makers do not rely solely on the provided dimensions but can generate another underlying dimension that influences their decisions (Li, 2016; Rao et al., 2014). Mechanisms regarding the additional dimension of negative emotions-especially in intertemporal choices for losses-have been proposed to explain why people prefer immediate negative events and, in particular, why they tend to be impatient for negative events to occur (Hardisty, 2017; Harris, 2012; Loewenstein, 1987; Sun et al., 2015). Researchers have also begun to consider the cognitive element in order to elucidate the mechanism of negative discounting (Harris, 2012; Sun et al., 2015). However, to the best of our knowledge, the cognitive element has yet to be specifically explored. Based on Sun et al. (2015)'s findings on outgrowth and the possible explanation of rumination on negative discounting, the present study explored the psychological mechanism of negative discounting from the perspective of modifying the representation space. This was done by introducing rumination through designing the experimental condition of something tying one up. Our findings, together with those reported in Sun et al. (2015), add evidence to the notion that the outgrowth account of pain minimization is a promising account that can help explain negative temporal discounting.

Our findings seem to contradict the discounting model. We reasoned that participants in the present study did not simply obey the minimizing principle of discounting and integrating (i.e., integrating the reward amount and time-delay attributes to create a discounted value for each option, as defined by Stevens, 2016, in making intertemporal choices for losses). The present study showed that the participants did not seem to adopt a strategy of minimizing loss to make decisions. Our findings provided supportive evidence that people-at least those represented in this study-would prefer to undergo an unpleasant event immediately not because the overall negative utility of the chosen option (immediate negative event) was small, but because 
undergoing unpleasant experiences immediately can free up more time and energy to better cope with something tying one up.

Our results, and the theoretical account we propose, can be easily understood in light of the Robbers Cave study (Sherif et al., 1961). A simple but effective approach for promoting cooperation emerged from Sherif et al's experiment, namely, that the presence of outgroup threat fosters cooperation (see also Brewer \& Kramer, 1985). An analogous approach for encouraging people to experience a negative event earlier was reported in our study: The addition of something tying one up (cf. outgroup threat) results in a change from choosing a deferred negative event (cf. competition) to choosing an immediate negative event (cf. cooperation). These approaches each promote a difficult but beneficial (and possibly going against human nature) behavior by adding a third "hand" (i.e., threat or care).

The reliability and reproducibility of the obtained free from care account of a negative event suggest that this account can be used as a simple but effective behavioral nudge: simply adding something tying one up will nudge people to choose the immediate negative event. Many negative events occur across various life domains, and a preference for delayed negative events can elicit great individual and societal costs. For instance, in educational settings, academic procrastination is common and may result in academic failure (Steel, 2007). There is high demand for interventions to reverse these preferences. Tax returns and journal reviews are examples of tasks that share characteristics of the English oral exam (negative event) in the present investigation. For instance, many reviewers accept invitations to perform a review for a journal weeks or months in advance but delay their work because such reviews (similar to an English oral exam) are time- and energyintensive. However, these delays can be challenging for the authors, especially young scholars who find themselves in a publish-or-perish environment. If "something tying one up" was added to reviewers' schedules, they might accelerate the review process rather than wait. Filing tax returns is another example. The filing process can be timeconsuming, confusing, and in some cases, expensive (Demshock, 2016; Lorence, 2015). If “something tying one up" was added to a person's schedule, then the person may engage more actively in the filing process rather than defer it. Thus, an ever-increasing waste of effort and money could be avoided. In summary, the findings of this study add to the long list of important contributions regarding nudge techniques (Leonard, 2008). Based on our findings, we hope to join those who have sought to facilitate decisions around health, wealth, and happiness to solve some of society's major problems (Thaler \& Sunstein, 2008).

Despite its contributions, several limitations of this research leave room for future consideration. First, we adopted an English oral exam scenario as a loss event to explore a free from care account of negative discounting. Our analysis should thus be extended from preferences for oral exams to preferences for monetary, air-quality, and garbageloss events (Guyse \& Simon, 2011); recently, several studies have demonstrated that people typically exhibit negative time preferences for monetary and air-quality losses (Hardisty \& Weber, 2009; Sun et al., 2015). Furthermore, the negative discount phenomenon can manifest in positive and negative domains (Loewenstein \& Prelec, 1993; Read
\& Powell, 2002). Research in other domains is required to confirm the reliability of our findings and to explore the mechanisms underlying negative discounting.

Second, in Study 4, the care event which induced the participants' care about being tied up with something was set on the 10th day beyond the time interval,. However, the influence of "beyond the time interval" should have a boundary condition; this issue presents an avenue for subsequent research. For instance, the "beyond the time interval" condition could be influenced by temporal distance between the timing of a care event and the deadline of a negative event (whether near or far). According to the theory of psychological distance, temporal distance is a basic dimension of psychological distance; events that are distant from individuals are represented as high-level construals, whereas near events are represented as low-level construals (Liberman et al., 2007). Many studies have explored the effect of psychological distance on preferences (Liberman et al., 2002; Trope \& Liberman, 2003). This form of distance may constitute a boundary condition of "beyond the time interval" and should be explored in greater detail.

Third, Study 5 (the field study) provided evidence for our working hypothesis. However, confounding variables should be addressed (i.e., the influence of the first exam on the second exam may have resulted in an order effect). Future research could adopt a more carefully controlled experimental design to measure the participants' emotions after the first exam to confirm the mechanisms of negative discounting.

Finally, we believe that a free from care account represents an important potential mechanism behind negative discounting. By manipulating the degree to which one is tied up with something (Studies 2 and 3 ) and the timing of being tied up (Study 4), the mechanism of negative discounting can be evaluated from other perspectives. For example, Loewenstein and Prelec (1993) proposed a model for preferences over outcome sequences that involved abandoning the additive assumption. They found that people typically favor sequences that improve over time. In that case, an oral exam and a care event could be framed as a dual-outcome sequence. Apart from the sequence effect, we also noticed that the participants demonstrated negative discounting behavior in Study 1 when no manipulation occurred. Therefore, the results of Study 1 indicated that our findings may not simply be a matter of a free from care account. Indeed, we believe that other factors (e.g., individual differences) might modulate the relationship between a negative event and its associated behavioral consequences. For example, our findings could be moderated by the participants' personality traits (e.g., impulsive vs. protracted; Strunk et al., 2013). Impulsive individuals may be more likely to choose to experience a negative event earlier. Relatedly, procrastination suggests that people will voluntarily delay completion of a planned event despite adverse anticipated consequences (Steel, 2007). Subsequent studies on negative discounting should thus incorporate personality traits to identify potential moderating roles. 


\section{ACKNOWLEDGEMENTS}

This research was partially supported by the National Natural Science Foundation of China (Nos. 71761167001, 71971099, $71571087,71601121,31471005)$, the Major Project of National Social Science Foundation of China [19ZDA358; 18ZDA332; 17ZDA325], Foundation Major Cultivation Project of Guangdong Province, China (2017A030308013), Featured Innovation Grant of Guangdong Education Department(2018WQNCX027), Key Projects of National Social Science Foundation of China [16AZD058] and Poverty Alleviation Program of Chinese Academy of Sciences (KFJ-FP-201906). The authors thank Fei Tan, Lei Tan, Qiang Xing for their assistance with data collection and interpretation, and Xing-Yun Song for his assistance with the translation and expression of English.

The authors declare that they have no conflicts of interest with respect to their authorship or the publication of this article.

Hai-Long Sun, Ai-Mei Li, and Si-Chu Shen contributed equally to this work.

\section{REFERENCES}

Berns, G. S., Chappelow, J., Cekic, M., Zink, C. F, Pagnoni, G., \& MartinSkurski, M. E. (2006). Neurobiological substrates of dread. Science, 312, 754-758. doi: 10.1126/science.1123721 الس

Brewer, M. B., \& Kramer, R. M. (1985). The psychology of intergroup attitudes and behavior. Annual Review of Psychology, 36, 219-243. doi: 10.1146/annurev.ps.36.020185.001251 الس السلسلس

Demshock, H. M. (2016). Considering moving abroad? Examining the tax implications before finalizing your decision. Journal of Financial Service Professionals, 70, 12-15. الس السلسلس

Faul, F., Erdfelder, E., Buchner, A., \& Lang, A. G. (2009). Statistical power analyses using $G^{*}$ Power 3.1: Tests for correlation and regression analyses. Behavior Research Methods, 41, 1149-1160. doi: 10.3758/BRM.41.4.1149 سلس

Franco-Watkins, A. M., Mattson, R. E., \& Jackson, M. D. (2015). Now or later? Attentional processing and intertemporal choice. Journal of Behavioral Decision Making, 29, 206-217. doi:10.1002/bdm.1895 Wلس

Frederick, S., Loewenstein, G., \& O'Donoghue, T. (2002). Time discounting and time preference: A critical review.Journal ofEconomic Literature, 40, 351-401. doi: 10.1257/002205102320161311

Gross, J. J., \& Levenson, R. W. (1997). Hiding feelings: The acute effects of inhibiting negative and positive emotion. Journal of Abnormal Psychology, 106, 95-103. doi: 10.1037/0021-843X.106.1.95 السلسلس

Guyse, J. L., \& Simon, J. (2011). Consistency among elicitation techniques for intertemporal choice: A within-subjects investigation of the anomalies. Decision Analysis, 8, 233-246. doi: 10.1287/ deca.1110.0212

Hardisty, D. J. (2017). The bright side of dread: Anticipation asymmetries explain why losses are discounted less than gains. In P. Moreau, \& S. Puntoni (Eds.), Advances in consumer research (Vol. 44, pp. 185-189). Association for Consumer Research.

Hardisty, D. J., \& Weber, E. U. (2009). Discounting future green: Money versus the environment. Journal of Experimental Psychology: General, 138, 329-340. doi: 10.1037/a0016433 السلسلسلسال

Hardisty, D. J., \& Pfeffer, J. (2016). Intertemporal uncertainty avoidance: When the future is uncertain, people prefer the present, and when the present is uncertain, people prefer the future. Management Science, 63, 519-527. doi: 10.1287/mnsc.2015.2349 Шلس

Hardisty, D. J., Appelt, K. C., \& Weber, E. U. (2013). Good or bad, we want it now: Fixed-cost present bias for gains and losses explains magnitude asymmetries in intertemporal choice. Journal of Behavioral Decision Making, 26, 348-361. doi: 10.1002/bdm. 1771 1لسلسلسلس

Harris, C. R. (2012). Feelings of dread and intertemporal choice. Journal of Behavioral Decision Making, 25, 13-28. doi: 10.1002/ bdm.709 سلس سلس

Harvey, C. M. (1994). The reasonableness of non-constant discounting. Journal of Public Economics, 53, 31-51.

Jevons, W. S. (1905). Essays on economics. Macmillan.

Kahneman, D. (1973). Attention and effort. Prentice-Hall.

Kahneman, D., \& Tversky, A. (2000). Choices, values, and frames. Cambridge University Press.

Leonard T (2008) Book review: Richard H. Thaler, Cass R. Sunstein, Nudge. Constitutional Political Economy 19, 356-60. doi: 10.1007/ s10602-008-9056-2 2

Li, S. (2016). An equate-to-differentiate way of decision-making. East China Normal University Press.

Liberman, N., Trope, Y., \& Stephan, E. (2007). Psychological distance. In A. W. Kruglanski \& E. T. Higgins (Eds.), Social psychology: Handbook of basic principles (Vol. 2; pp. 353-383). Guilford Press.

Liberman, N., Sagristano, M. D., \& Trope, Y. (2002). The effect of temporal distance on level of mental construal. Journal of Experimental Social Psychology, 38, 523-534. doi: 10.1016/S00221031(02)00535-8 الس الس

Loewenstein, G. (1987). Anticipation and the valuation of delayed consumption. The Economic Journal, 97, 666-684. doi:10.2307/2232929 السلسلس

Loewenstein, G., \& Prelec, D. (1992). Anomalies in intertemporal choice: Evidence and an interpretation. The Quarterly Journal of

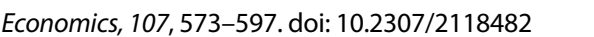

Loewenstein, G. F., \& Prelec, D. (1993). Preferences for sequences of outcomes. Psychological Review, 100, 91-108. doi: 10.1037/ 0033295X.100.1.91

Lorence, R. (2015). Useless/redundant/unread information returns and protective filings. Journal of Investment Compliance, 16, 40-48. doi: 10.1108/JOIC-01-2015-0003 الس السلسلس

Luce, R. D. (1959). Individual choice behavior: A theoretical analysis. Wiley.

Mazur, J. E. (1984). Tests of an equivalence rule for fixed and variable reinforcer delays. Journal of Experimental Psychology: Animal Behavior Processes, 10, 426-436. doi: 10.1037/0097-7403.10.4.426 Uلس

Mischel, W., Grusec, J., \& Masters, J. C. (1969). Effects of expected delay time on the subjective value of rewards and punishments. 
Journal of Personality and Social Psychology, 11, 363-373. doi: 10.1037/h0027265 المالسلس

Preacher, K. J. \& Hayes, A. F. (2004). SPSS and SAS Procedures for estimating indirect effects in simple mediation model. Behavior Research Methods, Instruments, \& Computers, 36, 717-731.doi: 10.3758/BF03206553 السلسلس

Rao, L. L., Zheng, Y., Zhou, Y., \& Li, S. (2014). Probing the neural basis of superstition. Brain Topography, 27, 766-770. doi:10.1007/ s10548-013-0332-8 الس الس

Read, D., \& Powell, M. (2002). Reasons for sequence preferences. Journal of Behavioral Decision Making, 15, 433-460. doi: 10.1002/ bdm.429 سلس

Sherif, M., Harvey, O. J., White, B. J., Hood, W. R., \& Sherif, C. W. (1961). Intergroup conflict and cooperation: The Robbers Cave experiment (Vol. 10). The University Book Exchange.

Siemer, M. (2008). Beyond prototypes and classical definitions: Evidence for a theory-based representation of emotion concepts. Cognition\&Emotion,22,620-632.doi:10.1080/02699930701440067 Wلس

Steel, P. (2007). The nature of procrastination: A meta-analytic and theoretical review of quintessential self-regulatory failure. Psychological Bulletin, 133, 65-94. doi: 10.1037/0033-

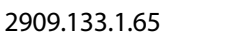

Stevens, J. R. (2016). Intertemporal similarity: Discounting as a last resort. Journal of Behavioral Decision Making, 29, 12-24. doi: 10.1002/bdm.1870 السلسلس

Strunk, K. K., Cho, Y., Steele, M. R., \& Bridges, S. L. (2013). Development and validation of a $2 \times 2$ model of time-related academic behavior: Procrastination and timely engagement. Learning and Individual Differences, 25, 35-44. doi: 10.1016/j.lindif.2013.02.007 سلس الس

Sun, H. Y., Li, A. M., Chen, S., Zhao, D., Rao, L. L., Liang, Z. Y., \& Li, S. (2015). Pain now or later: An outgrowth account of pain-minimization. PLOS One, 10, e0119320. doi: 10.1371/journal.pone.0119320 السلسلسلسا

Thaler, R. (1981). Some empirical evidence on dynamic inconsistency. Economics Letters, 8, 201-207. doi: 10.1016/01651765(81)90067-7 الس الس الس

Thaler, R. H, \& Sunstein, C. R. (2008). Nudge: Improving decisions about health, wealth, and happiness. Yale University Press.

Trope, Y., \& Liberman, N. (2003). Temporal construal. Psychological Review, 110, 403-421.doi: 10.1037/0033-295X.110.3.403 البلسلسلة

RECEIVED 30.04.2019| ACCEPTED 28.02.2020 